\title{
Remembering Dr Herbert A. Kirst (22 September 1944-25 September 2019)
}

\author{
James (Jim) McAlpine ${ }^{1}$
}

Received: 1 November 2019 / Accepted: 1 November 2019 / Published online: 6 January 2020

(c) The Author(s), under exclusive licence to the Japan Antibiotics Research Association 2020

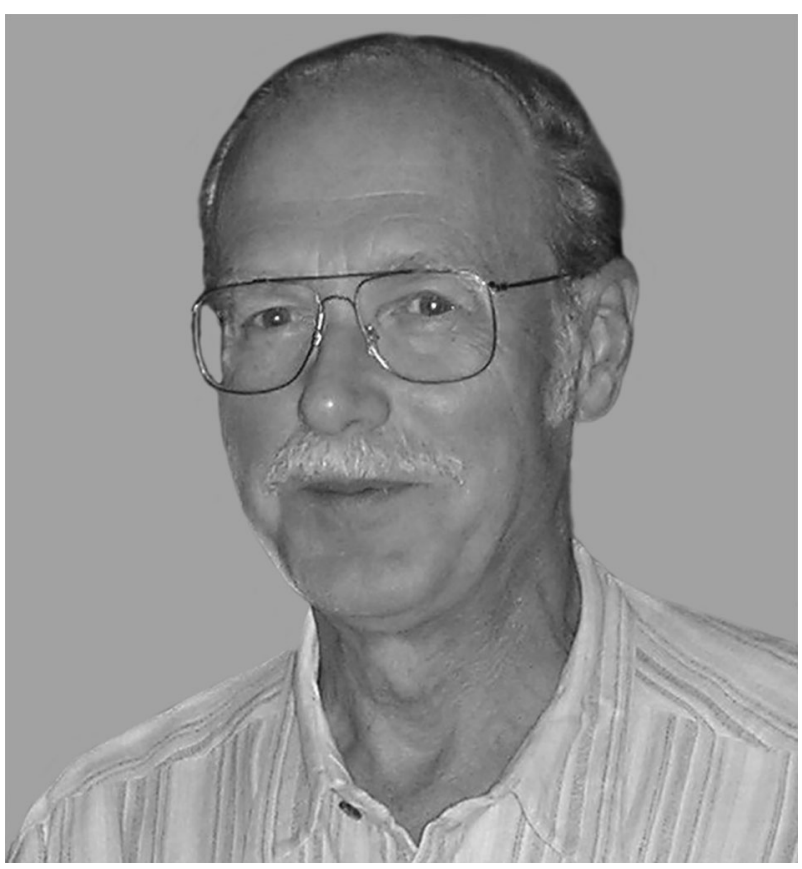

Herbert A. Kirst was born 22nd of September, 1944 in St. Paul, MN and educated at the University of Minnesota (BS, 1966) Harvard University (PhD, 1971) and postdoctoral studies at California Institute of Technology. He then joined Eli Lilly \& Co. as a Research Scientist and worked on antibiotic chemistry for 30 years, moving to the Dow Elanco group when it was split off. At Eli Lilly, he became an expert in the fermentation and analogs of erythromycin and other macrolides. He continued his interest in antibiotics at Dow Elanco where he was heavily involved with the discovery and development of the Spinosyns, tetracyclic polyketides from Saccharopolyspora spinosa with good activities against insects, mites, and other ectoparasites.

Herb was a passionate scientist, publishing more than 50 original articles and over 40 reviews and book chapters. He also organized meetings on macrolide chemistry and biology. He was on the Scientific Advisory Board of Cempra Inc. and was a member of the American Chemical Society, the American Society of Microbiology, the American Association for the Advancement of Science, and the New York Academy of Science. He was a member of our Editorial Board since 1995 and acted as Section Editor (together with our current Editor-in-Chief) for Structure Determination and Chemical Synthesis manuscripts. In 2018 Dr Kirst was elected to Emeritus status on the Board. In 2005 he was awarded the Microbial Chemistry Medal by the Kitasato Institute.

He was very devoted to his wife, Peggy Hillman, a strongly committed labor lawyer involved in many social programs. They enjoyed cycling together and went on several trips including one to Southwestern France. Tragically Peggy was killed while cycling when hit by an intoxicated driver on August 31st' 2015. At that time Herb was already showing the early signs of Parkinson's Disease, and he passed away quietly in the early hours of September 25th, 2019. Herb befriended many colleagues, whom he generously helped. His expertize in antibiotics will be missed as the world faces rising antibiotic resistance and scientists turn to examining natural products for new antibiotics.

With edits from Prabha Fernandes and Mary Baim.
James (Jim) McAlpine

mcalpine@uic.edu

1 Department of Pharmaceutical Sciences, College of Pharmacy, University of Illinois at Chicago, Chicago, IL, USA 